\title{
Polymer modified paste fill for isolation of waste disposal sites
}

\author{
M. Fall Department of Civil Engineering, University of Ottawa, Canada \\ J.C. Celestin Department of Civil Engineering, University of Ottawa, Canada \\ F.S. Han Department of Civil Engineering, University of Ottawa, Canada
}

\begin{abstract}
Engineering of waste containment facilities such as solid and hazardous waste landfills and mine waste repositories usually requires the construction of a barrier (liner, cover). The liners are usually needed to minimise the downward flux of contaminants, while the covers generally limit the accessibility of fluid (e.g. rain water) to the waste. The barrier will drastically reduce the potential impact of the waste disposal on the environment (e.g. groundwater, surface water, and ecosystem). In this paper, the results of research on potential use of polymer modified paste fill (PMP) as barrier material for waste containment facilities are presented and discussed. The saturated hydraulic conductivity of PMP mixes with different SAP (super absorbent polymer) contents were investigated at various compaction degrees. Furthermore, the relative cost and the resistance of the PMP materials to environmental stresses (freeze-thaw and wet-drying cycles) were evaluated. Valuable and encouraging results were obtained. The results have shown that possibilities of using PMP as barrier materials appeared very promising owing their good hydraulic performance, relative good resistance to environmental stresses and the reduced cost from the low admixture amount necessary to further improve this performance. The cost of a conventional barrier material made using bentonite (12\%) and sand is higher than any of the studied amounts of SAP required to be mixed in the paste fill to achieve the recommended low conductivity. The benefit realised could be estimated to 98, 96 and 90\% when using PMP material containing 0.10, 0.20 and 0.5\% of SAP polymer.
\end{abstract}

\section{Introduction}

Despite the tremendous progress that has been made in the use of tailings as construction materials in the past decades, there is still a need to find other alternative usages of tailings as construction materials in mining operations or civil engineering constructions due to the high quantity of tailings produced by the mining industry. An alternative usage of tailings as construction material would be to use non-acid generating paste fill without cement as barrier (liner or cover) materials for waste containment facilities. Previous studies (Fall et al., 2009a) performed on non cemented paste fill materials revealed that the permeability of paste fill is in the range of $10^{-4}$ to $10^{-6} \mathrm{~cm} / \mathrm{s}$, i.e. close to the minimum permeability value $\left(10^{-7} \mathrm{~cm} / \mathrm{s}\right)$ required for liner design according to the Environmental Protection Agency. This means, as soil permeability is mainly governed by the proportion and the nature of the finer fraction, paste fill mixed with swelling materials like polyacrylates (a super absorbent polymer, SAP) could be potentially used as barrier materials for waste containment facilities, in regions where preferred materials are not available for the design. However, the recycling of paste fill mixed with SAP as barrier materials has not received much attention. Hence, a research program has been conducted at the University of Ottawa to study the suitability of the mixtures of paste fill and SAP as liner and cover for waste containment facilities. If paste fill can be recycled in engineering barriers constructions, then significant amount of tailings can be reutilised in the mining waste management, which helps to reduce environmental and geotechnical problems as well as costs associated with surface tailings management. One part of the obtained results, i.e. those related to one of the key parameters (saturated hydraulic conductivity) used to judge the suitability of any material as liner or cover will be presented. 


\section{Materials and experimental procedures}

\subsection{Materials}

\subsubsection{Tailings}

In this paper, non-acid generating tailings material is mainly used. The grain size distribution (determined by sieve and hydrometer tests in accordance to ASTM C 136 and ASTM D 422-63) of the tailings used is shown in Figure 1. The weight proportion of particles with diameter lower than $20 \mu \mathrm{m}$ is around $40 \%$. This is higher than the minimum proportion required to develop paste fill. It can be observed that the tailings, with about $45 \mathrm{wt} \%$ fine particles $(<20 \mu \mathrm{m})$, can be classified as medium tailings. Moreover, the tailings were tested for some index properties (liquid and plastic limits) by following ASTM D 4318. From the experimental work, the used tailings can be classified as sandy silts of low plasticity; ML in the Unified Soil Classification System (UCCS). ML is characteristic for tailings from hard rock metal mines.

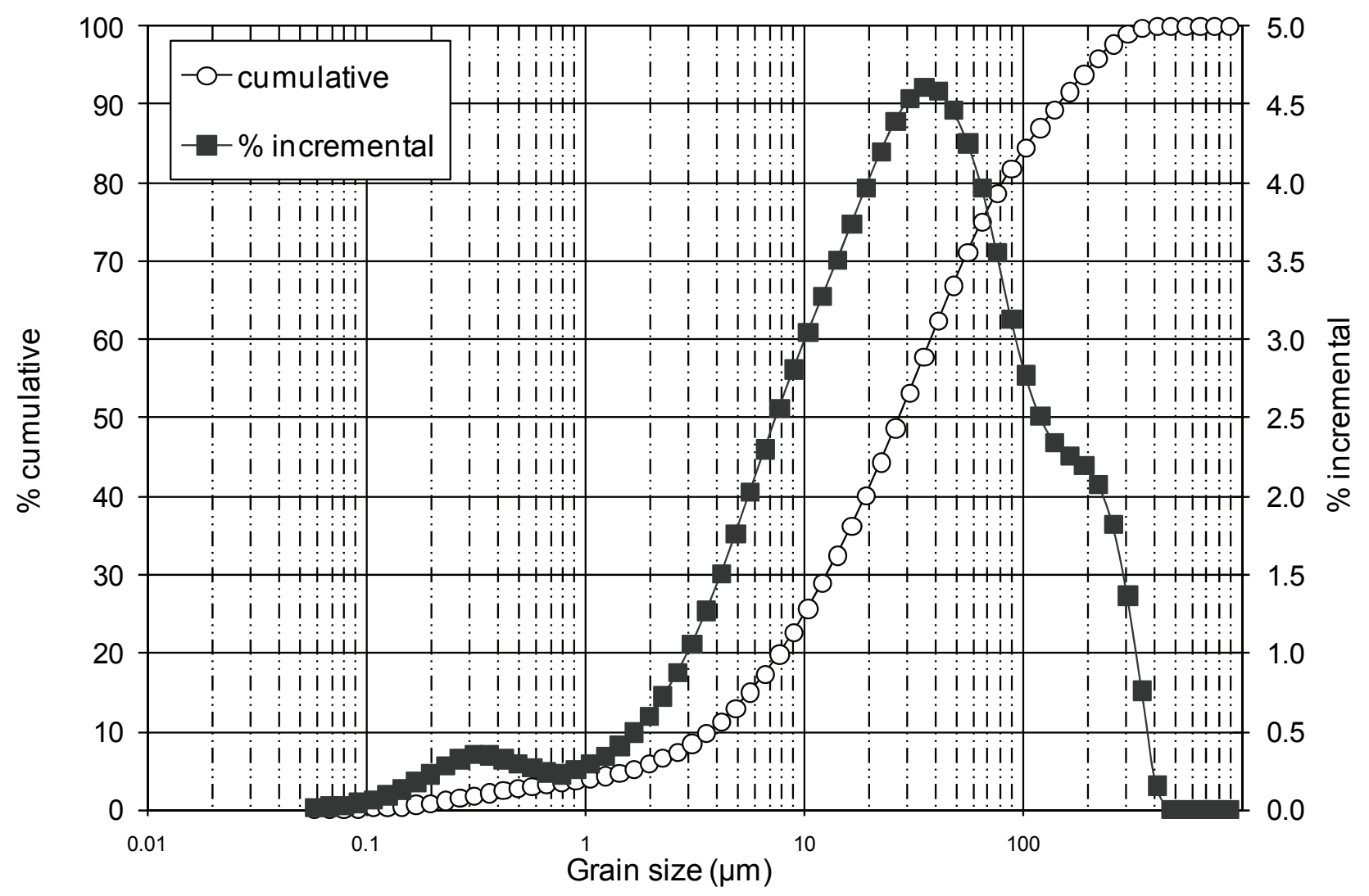

Figure 1 Grain size distribution of the tailings used

\subsubsection{Polymer material (sodium polyacrylates)}

Commercially available cross-linked insoluble sodium polyacrylates (a SAP) with a free swell capacity of $250 \mathrm{~g} / \mathrm{g}$ in deionised water was used. These SAPs are a group of polymeric materials that have the ability to absorb a significant amount of liquid from the surroundings and retain the liquid within their structure without dissolving. About $95 \%$ of the SAP world production is used as urine absorber in disposable diapers (Daniels et al., 2003). The ion exchange capacity in the SAP confers a hydrophobic nature and good retention properties. The strong ion exchange capability also allows for heavy metals to be bound (ARK, 2003). As SAP is solvated, chains unfold and ionic repulsive forces expand its molecules, which create large absorption capacities. Gellation occurs from multiple hydrations of the lattice structure of the molecule (ARK, 2003). Therefore, aside from the blocking of pores, fluid absorption may significantly delay transport. 


\subsubsection{Mixing water}

Deionised water was used for the mixing of the PMP material to ensure that no chemical parameters were involved during the series of tests.

\subsection{Preparation of the specimens}

The paste fill was hydrated alone first. Once hydration was completed, SAP was added and mixing continued until there was uniform distribution. After compaction in a proctor mould, a cutting cylinder of $5 \mathrm{~cm}$ in diameter was used to sample undisturbed cores for hydraulic conductivity tests. Thereafter, the specimens were removed from the cylindrical sampling tube by using a mechanical press and stored in a polyethylene package for 24 hours prior to conducting hydraulic conductivity testing. Hydrated samples were trimmed and installed in a triaxial cell where the hydraulic conductivity measurement took place.

\subsection{Testing methods and procedures}

\subsubsection{Compaction tests}

Compaction was performed following ASTM D 698-00a for Standard Proctor. The rational of compaction was to increase the dry density and thereby to reduce the void in the material. To come up with the optimum moisture content (OMC), initially, several specimens of raw paste tailings (paste fills) were prepared and tested at water contents from the range of 4 to $24 \%$ in gradual increments of $2 \%$ of water. The compaction curve drawn from these tests showed that the wet of optimum lied around the $20 \%$ moisture content and a maximum density of $1,580 \mathrm{~kg} / \mathrm{m}^{3}$ was determined. For proper characterisation of compaction behaviour of PMP, tests were conducted at least on two points at the wet side, two points at the dry side and at the optimal water content. The water content from the optimum was considered to ensure that all tests have taken place in a range susceptible to lead to maximum dry density (i.e. minimum void ratio) for all other tests. Thus, the indication of maximum density from the raw paste tailings was used as a reference for all tests with PMP. Each test was repeated at least twice and the average value was considered as the water and dry density of the sample tested.

\subsubsection{Hydraulic conductivity tests}

The flexible wall permeameter principle was used by following ASTM D 5084-00 to perform hydraulic conductivity tests. The effluent head was kept constant at $10 \mathrm{kPa}$, while the influent head was calculated from a desired gradient to be applied as a function of the sample thickness. A constant hydraulic gradient of 30 (which had gradually increased to this final value) was applied by using controlled air pressure from the control panel. The effective stress maintained in the cell was an average of $130 \mathrm{kPa}$, which is a value that can be produced by overlying waste (Kashir and Yanful, 2001; Fall et al., 2009b) or found in the majority of tailings management facilities (Fall and Merkel, 2001; Qiu and Sego, 2001). Additional care was also taken to collect specimens as much as possible at the middle of the compaction mould so they can all be considered under the same compactive condition. Finally, hydraulic conductivity was calculated by using the constant head principle. Hydraulic conductivity was conducted over a range of water content at least plus or minus $4 \%$ OMC at different water content. Each hydraulic conductivity test was repeated at least two times and the average value was considered as the hydraulic conductivity of the sample tested.

\subsubsection{Freeze-thaw tests}

Fine grained soils, when exposed to freezing and thawing conditions, can experience alterations in their hydraulic conductivities (Wong and Haug, 1991; Benson and Othman, 1993). Such alterations of hydraulic properties are relevant in the design of barriers in cold climates. For this reason, a series of freeze-thaw tests was conducted on PMP mixtures to investigate the impact of freeze-thaw cycles on the hydraulic conductivity of the proposed barrier material. PMP mixes with proportions of SAP of $0.0,0.05,0.1,0.2$ and $0.5 \%$ were submitted to freeze-thaw conditions up to a concurrence of 5 cycles. The following procedure was adopted. Samples were first prepared at a water content that corresponded to the minimum hydraulic conductivity which was determined during previous compaction accompanied with hydraulic conductivity tests at $20^{\circ} \mathrm{C}$ temperature. Hydraulic conductivity tests were carried out over samples submitted to 1 and up to 5 cycles of freeze-thaw. Each test hydraulic conductivity test was repeated twice. ASTM D 6035-96 was 
followed during the freeze-thaw stress application by ascertaining that all ice lenses melted and moisture in the samples became at equilibrium. The thermal loading was applied tri-dimensionally under hermetic conditions to prevent modifications in the initial water content during the process of temperature change by enclosing the specimens in sealed plastic bags.

\subsubsection{Wet-dry tests}

The hydraulic conductivity of barriers for waste containments constructed in regions that are characterised by alternate wet and dry seasons can be adversely affected by desiccation cracks. For this reason, the effect of wet-dry cycles on the hydraulic conductivity of PMP was investigated. Samples were first prepared at a water content that corresponded to the minimum hydraulic conductivity which was determined during previous compaction accompanied with hydraulic conductivity tests at $20^{\circ} \mathrm{C}$ temperature. After measuring the initial hydraulic conductivity, the samples were removed from the permeameter and dried in an oven at $45^{\circ} \mathrm{C}$ for $24 \mathrm{~h}$. A $45^{\circ} \mathrm{C}$ drying temperature was selected to approximate hot summer temperatures and minimise the possible impacts of high temperature on the polymer material. After completion of the first drying, the specimens were cooled to room temperature prior to submergence in distilled water and their hydraulic conductivities were determined again. This completed the first cycle of testing and measurement. The wetting and drying cycles were repeated a number of times. The compacted PMP specimens were subjected to zero (as-compacted state), 1, 2, 3, 4 and 6 cycles of wetting and drying, respectively. Hydraulic conductivity determinations were made after each cycle. Each test (wet-dry and hydraulic conductivity testing) was carried out twice for all specimens to ensure the repeatability of the results.

\section{$3 \quad$ Results and discussion}

\subsection{Compaction test results}

The compaction curves obtained with different PMP mixes are presented in Figure 2. The plain paste fill $\left(0 \%\right.$ SAP) exhibits the highest dry density of $1,590 \mathrm{~kg} / \mathrm{m}^{3}$. As a content of $0.05 \%$ of SAP is added, the dry density recorded becomes $1,530 \mathrm{~kg} / \mathrm{m}^{3}$. A further increase of the SAP proportion to $0.1 \%$ leads to a detrimental decrease to $1,490 \mathrm{~kg} / \mathrm{m}^{3}$ of the dry density. It was noticed that as the SAP proportion is increased, a continuous decrease is recorded in the maximal dry density. The explanation, which can be attributed to this behaviour is the fact that the replacement of tailings with swollen SAP (density of dry SAP is already low, and when filled with water, the density becomes comparable to that of water), in the first period contributes significantly to a decrease of the specific gravity of the material to be compacted. In the second round, aside from filling voids, the SAP gel decreases the proximity that exists between tailings grains. Furthermore, during compaction, the SAP grains filled with water transform into gel that also absorb the energy supplied by the hammer by encompassing deformation and reinstating their former shape after the impact. Finally, as the amount of SAP is increased to $0.2 \%$ and up to $0.5 \%$, the pattern drawn by the compaction curve is reminiscent of the one exhibited by loose sands, but exaggerated. 


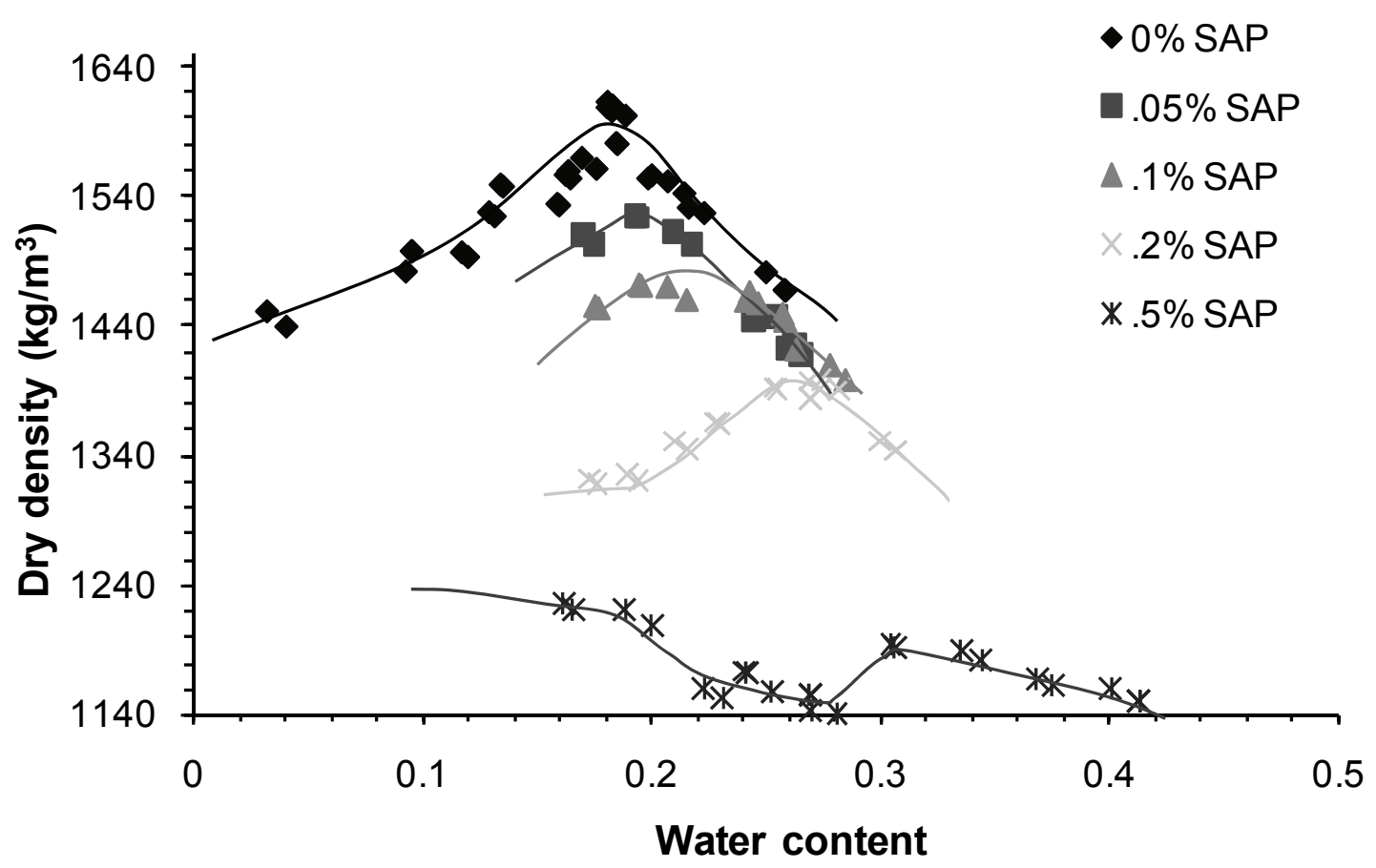

Figure 2 Effect of the SAP proportion on the characteristics of the proctor compaction of PMP

\subsection{Hydraulic conductivity test results}

The hydraulic conductivities of the PMP samples with SAP proportions of $0.05,0.1,0.2$ and $0.5 \%$ are presented in Figure 3. It can be observed that in each particular sample, the hydraulic conductivity decreases as the water content is increased during compaction. The trends of the hydraulic conductivity and the position where the minimum occurs for each mix appear to be a function of the polymer content and compaction water content. Another observation is that samples that contain more SAP tend to develop their lower conductivity at higher water content. This can be explained by the fact that more polymer in the mix leads to more water absorption, which causes the need for an increase in quantity to wet the grains of tailings. When comparing the different mix proportions, one can realise that as the percentage of SAP is increased, the hydraulic conductivity decreases. For instance, the values recorded for $0.0,0.05,0.1,0.2$ and $0.5 \%$ SAP are $4.1 \times 10^{-6}, 1.2 \times 10^{-7}, 1.0 \times 10^{-7}, 1.5 \times 10^{-8}$ and $6.1 \times 10^{-9} \mathrm{~cm} / \mathrm{s}$, respectively. Therefore, one can deduce that an increase in the polymer content has a positive effect on the hydraulic conductivity of the PMP. This positive effect can be explained by two processes that have taken place in the tested samples. First, the polymers are highly hydrophilic with a very high absorption capacity. They possess this feature from their cross linked structure where internal ions provoke osmosis, leading to water attraction that drives a considerable increase in volume. In the case of the polymers used in this study, the absorption capacity in deionised water is 250 times its own weight (Ark, 2003). Therefore, the polymer as a solute attracts and associates itself with the molecules of the solvent water. This association of the water molecules with the ions in the polymer develops repulsive forces internally in the polymer that expand its molecules, creating large absorption capacities (Ark, 2003). These ionic forces also have an effect of acting over the flow of water, causing it to slow down in the specimen. Adding to the charged ions effect, the expansion of the polymer contributes to a large extent, the filling of the pores in the previously compacted paste fill. 


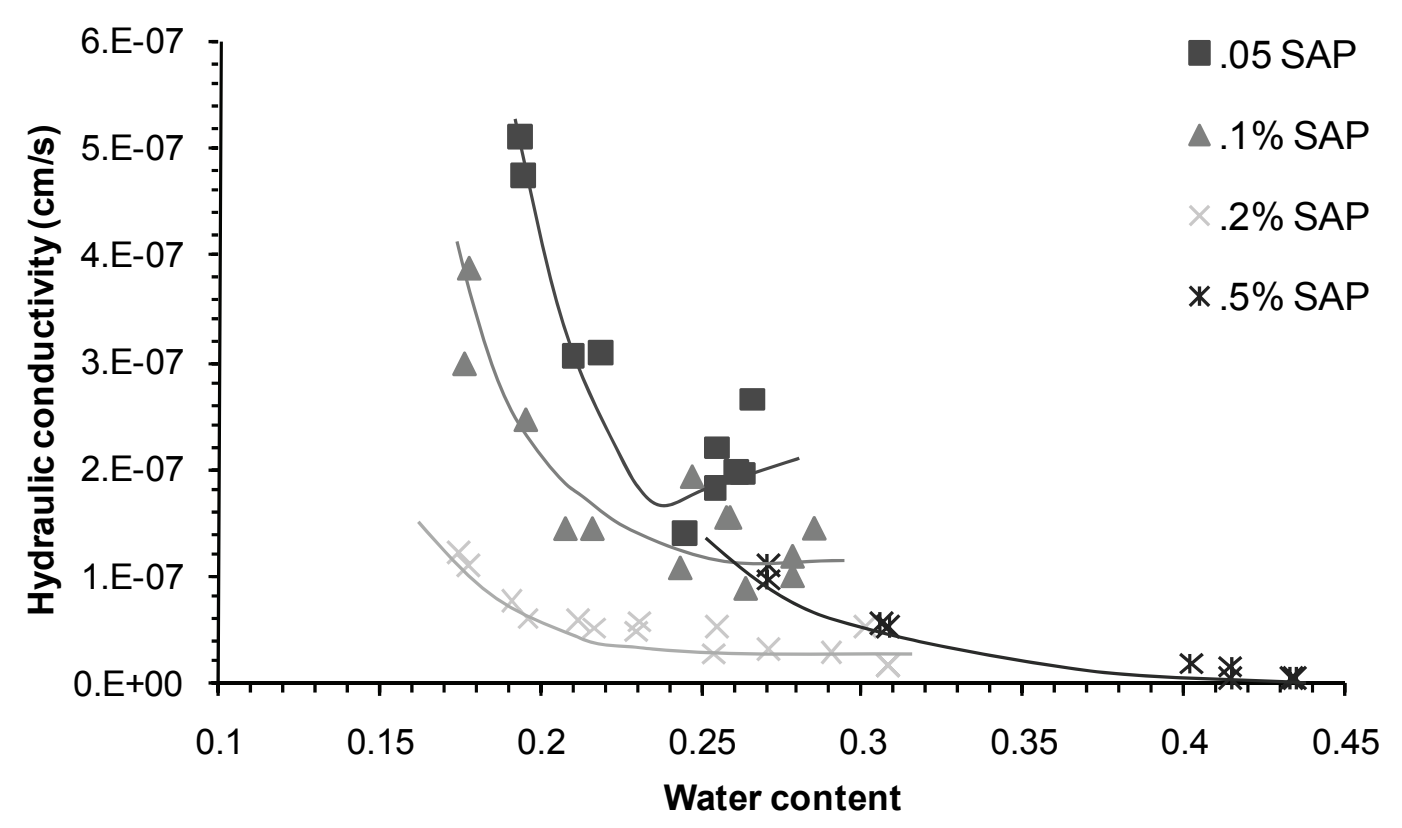

Figure 3 Effect of different SAP contents and water content on the hydraulic conductivity of PMP

\subsection{Effect of freeze-thaw cycles on the hydraulic conductivity of PMP}

The obtained results show that the hydraulic conductivity of PMP samples compacted wet of optimum is affected by the freeze-thaw cycles. However, the changes in the hydraulic conductivity are less than one order of magnitude. Furthermore, another important observation is that as the proportion of SAP is increased, the changes in hydraulic conductivity are even more apparent, even though prior to any application of freezethaw, the sample that contains a higher SAP content presents lower hydraulic conductivity. For illustration purposes, typical results of the impact of freeze-thaw cycles on the hydraulic conductivity and relative (normalised) hydraulic $\left(\mathrm{k}_{\mathrm{N}} / \mathrm{k}_{0}\right)$ of PMP containing 0.5 and $0.05 \%$ SAP compacted wet optimum are presented in Figures 4 and 5, respectively. The normalised hydraulic conductivity is expressed as the ratio between the permeability obtained in the thawed PMP after $\mathrm{N}$ cycles $\left(\mathrm{k}_{\mathrm{N}}\right)$ and the permeability initially in the unfrozen PMP $\left(\mathrm{k}_{0}\right)$. In the $0.5 \%$ SAP-PMP samples, a continuous increase in hydraulic conductivity is developed with the number of cycles as shown in Figure 4. This increase appears to become more important in the third cycle. The computed increase in hydraulic conductivity is found to be $715 \%$ and the factor that affects this increase is evaluated to be 8.15 and therefore, less than one order of magnitude. In the PMP mix series, $0.05 \%$ SAP represents the category with the lowest additive. The evolution of the hydraulic conductivity with freeze-thaw cycles (up to 5 cycles) is drawn in Figure 5. This graph shows a definite difference when compared to mixes that contain $0.5 \%$ SAP. The general trend would be a decrease in the hydraulic conductivity with freeze-thaw conditions. That is, the initial value of the hydraulic conductivity has a relative drop of $86 \%$, which corresponds to a decrease factor of 0.14 . Therefore, when taking a closer look of the change in the factor, this can be considered almost negligible if one takes into account, the factor of error that such a laboratory test can entail. This very low change in hydraulic conductivity may be attributed to the low water content present in the sample (24\%) and the presence of a small amount of SAP $(0.05 \%)$, which would infer that an increase in the SAP proportion leads to an increase in water content that would position the material in increased sensitivity to freeze-thaw cycles. The increase in permeability with freeze-thaw cycles observed for PMP mixes that contain $0.5 \%$ SAP can be attributed to the formation of a network of cracks within the frozen PMP specimens. Indeed, when the PMP is exposed to freezing and thawing, the pore water is turned into ice, and ice lenses can form. Ice forces will act on the PMP skeleton due to a 9\% volume increase during freezing. This freezing pressure will push some tailings particles apart. This will result in the cracking of the PMP skeleton, and also in an increase of the pore connectivity. This assumption is confirmed by visual observations of the PMP specimens. After each freezing or thawing, it was easy to discover with unaided eyes, that the small cracks appear to be more visible in the PMP samples. The cracks are more visible in samples with a higher SAP content. This can be understood from the fact that more SAP is capable 
of more water absorption from the mixtures. Water absorption converts the SAP into a gel of higher volume. The frozen gel will push the tailings grains apart, up to the appearance of cracks.

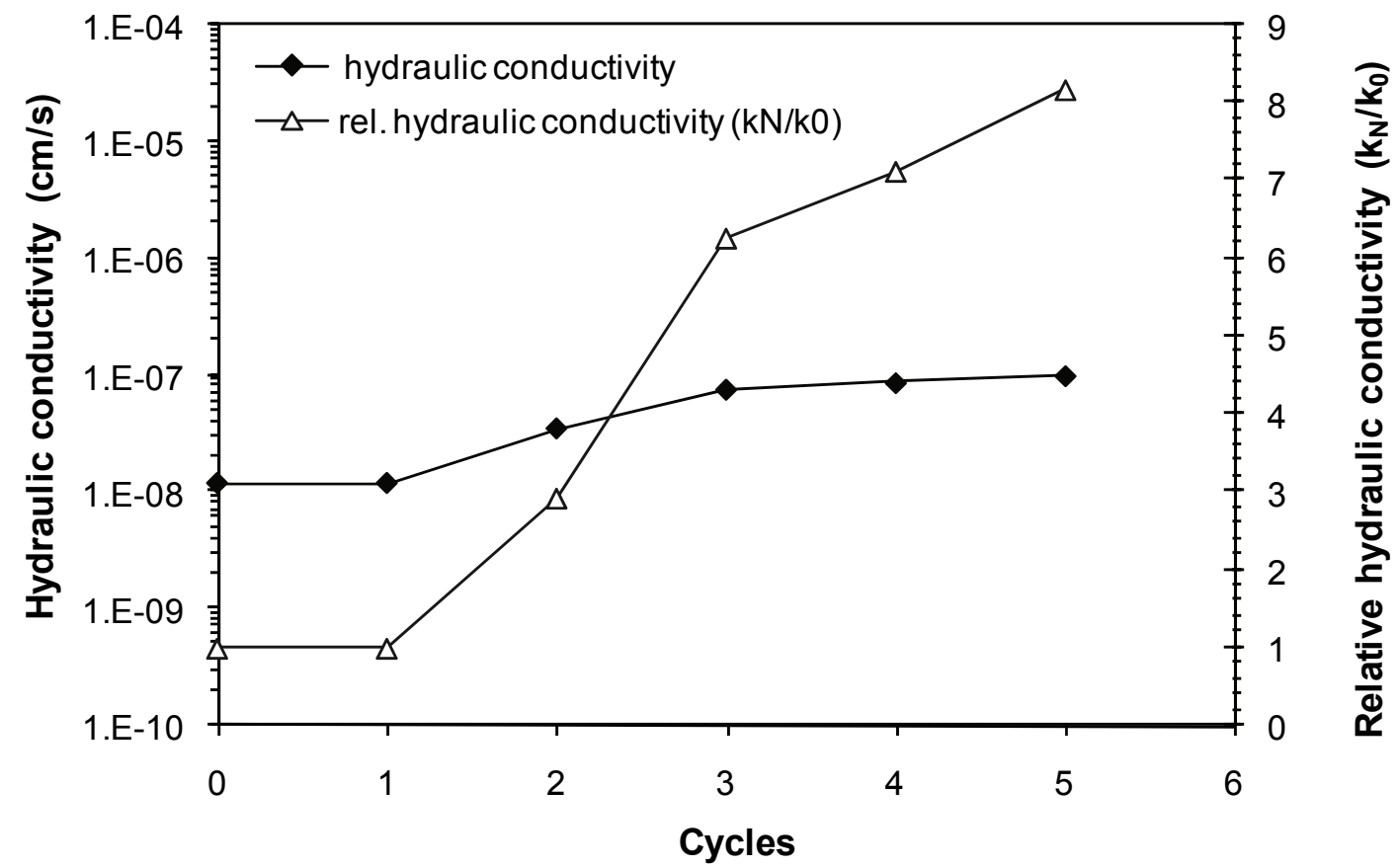

Figure 4 Evolution of the hydraulic conductivity and normalised hydraulic conductivity $\left(k_{N} / k_{0}\right)$ of 0.5\%SAP-PMP (30\% water content) with freeze-thaw cycles

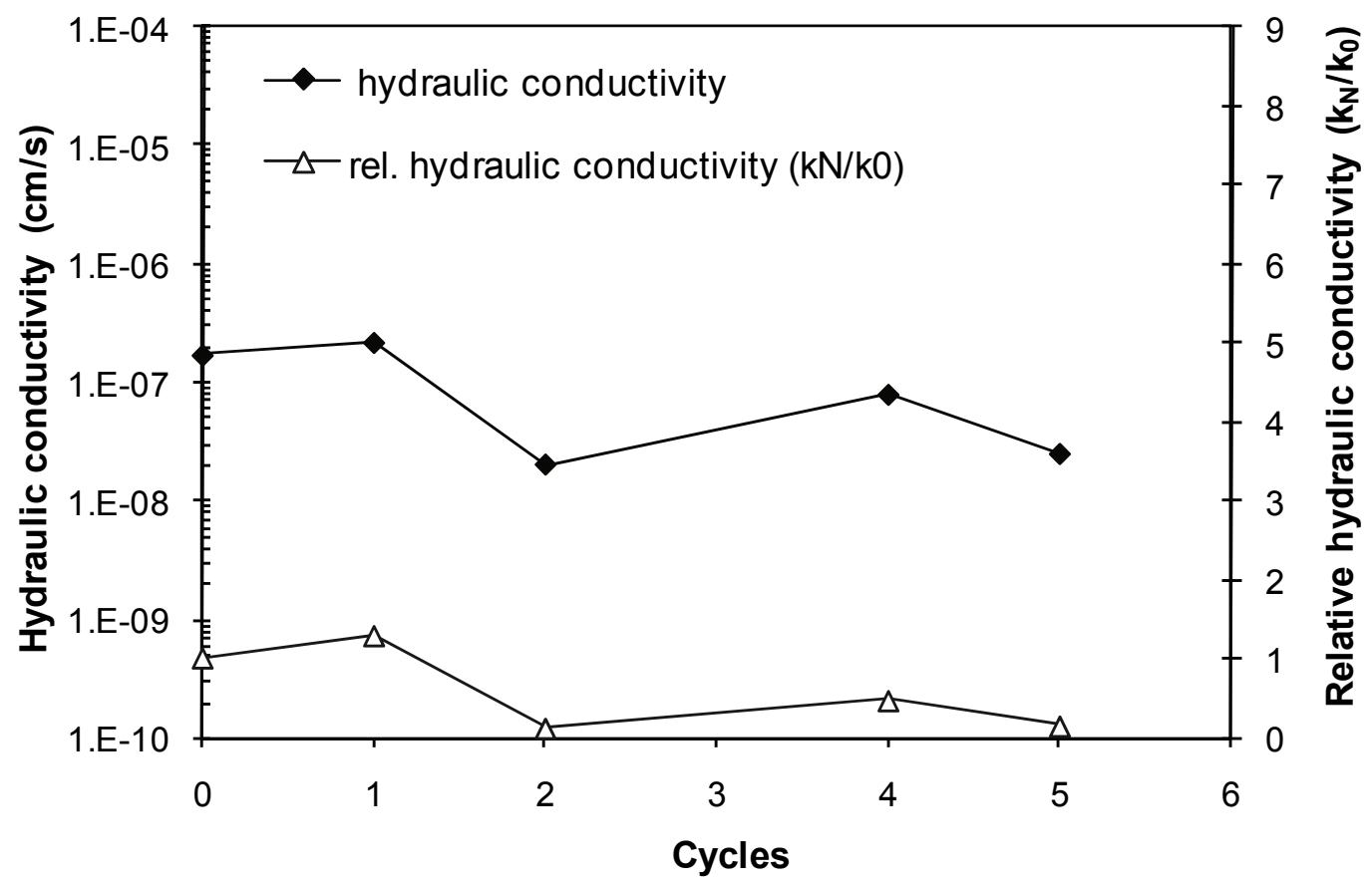

Figure 5 Evolution of the hydraulic conductivity and normalised hydraulic conductivity $\left(k_{N} / k_{0}\right)$ of $0.05 \%$ SAP-PMP with freeze-thaw cycles $(0.05$ SAP, $24 \%$ water content) 


\subsection{Effect of wet-dry cycles on the hydraulic conductivity of PMP}

The obtained results have shown that SAP has a positive influence on the wet-dry resistance of the proposed barrier material. For illustration purposes, an example that shows the typical results of hydraulic conductivity versus the number of wet-dry cycles as well as relative hydraulic conductivity $\left(\mathrm{k}_{\mathrm{N}} / \mathrm{k}_{0}\right)$ versus the number of wet-dry cycles for PMP that contain $0.5 \%$ SAP compacted wet optimum is shown in Figure 6 . It can be noted that the number of wet-dry cycles has no significant impact on the hydraulic conductivity and normalised hydraulic conductivity of PMP. The PMP samples underwent negligible changes in hydraulic conductivity. It is believed that this resistance of PMP to wet-drying stresses is associated with two mechanisms: (i) the self-healing processes that affect the various soil types by different degrees (Eigenbrod, 2003), and (ii) the SAP increases the moisture retention ability of the barrier thereby reducing the PMP shrinkage potential.

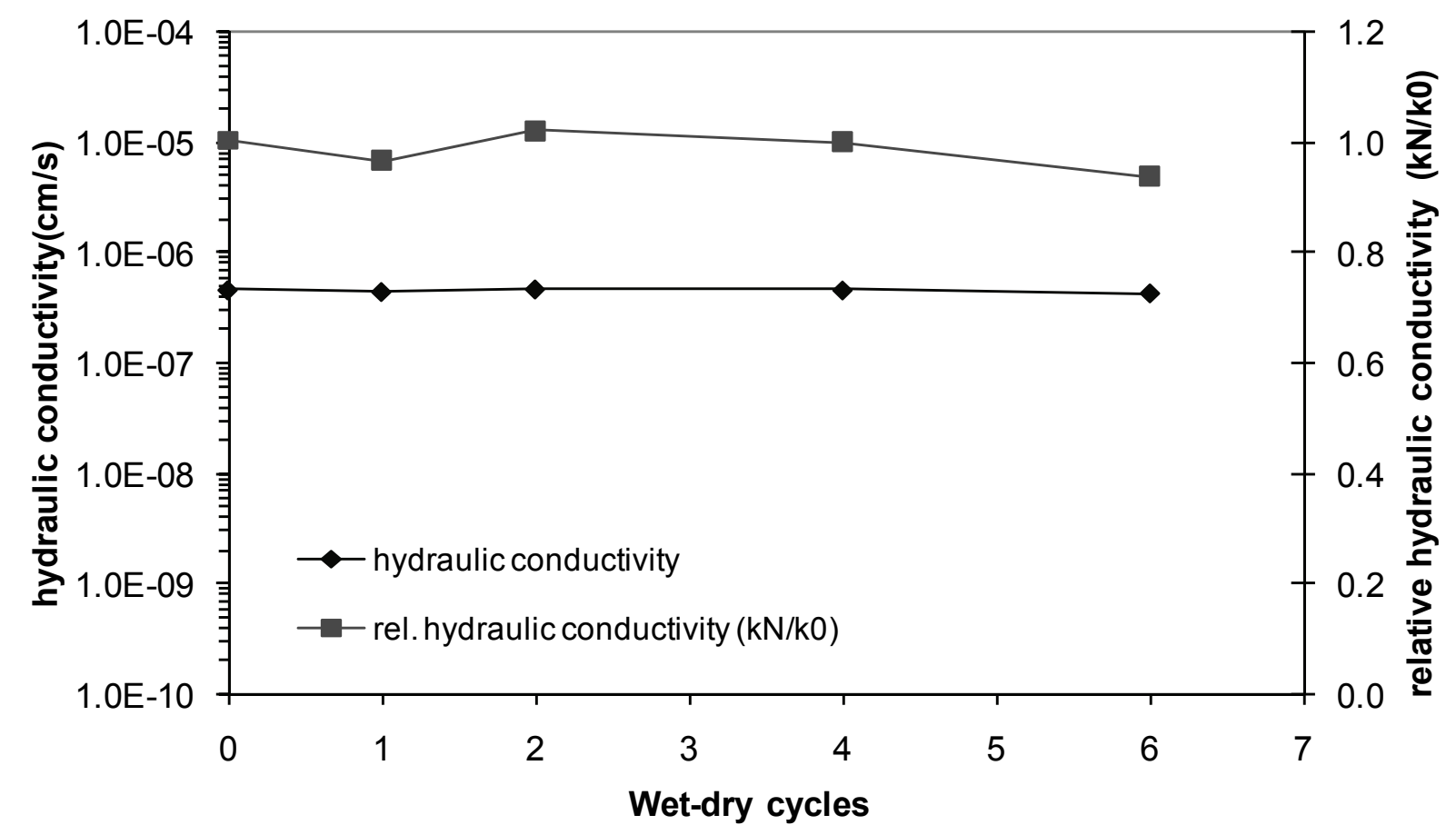

Figure 6 Evolution of hydraulic conductivity and relative hydraulic conductivity $\left(\mathrm{k}_{\mathrm{N}} / \mathrm{k}_{0}\right)$ of PMP with wetting-dry cycles $(0.05 \%$ SAP)

\subsection{Cost analysis}

In this study, various amounts of SAP are considered as acceptable concentrations, which confer to the polymer-paste fill a significant decrease in hydraulic conductivity until the minimum requirement is met for usage as barrier material. Therefore, in such conditions, is it beneficial to use such polymer-amended paste fill materials? To gain an idea of the cost positioning, the price per kilogram of PMP material is compared to one of a conventional barrier made of sand mixed with $12 \%$ of bentonite in total mass. It is necessary to understand that additive materials mainly control the prices in such mixtures. Using the $12 \%$ bentonite cost as reference, the benefit realised could be estimated as $99 \%$ (i.e. $0.05 \%$ SAP-PMP barrier material is $99 \%$ less expensive $12 \%$ bentonite-sand), $98 \%, 96 \%$ and $90 \%$ when using PMP material that contains $0.05 \%$, $0.10 \%, 0.20 \%$ and $0.5 \%$ of SAP polymer, respectively. The benefit is presented graphically for ease of comparison in Figure 7. It becomes obvious that $12 \%$ bentonite-sand material is more expensive than any of the studied amounts of SAP required to be mixed in the paste fill to achieve the recommended low conductivity. 


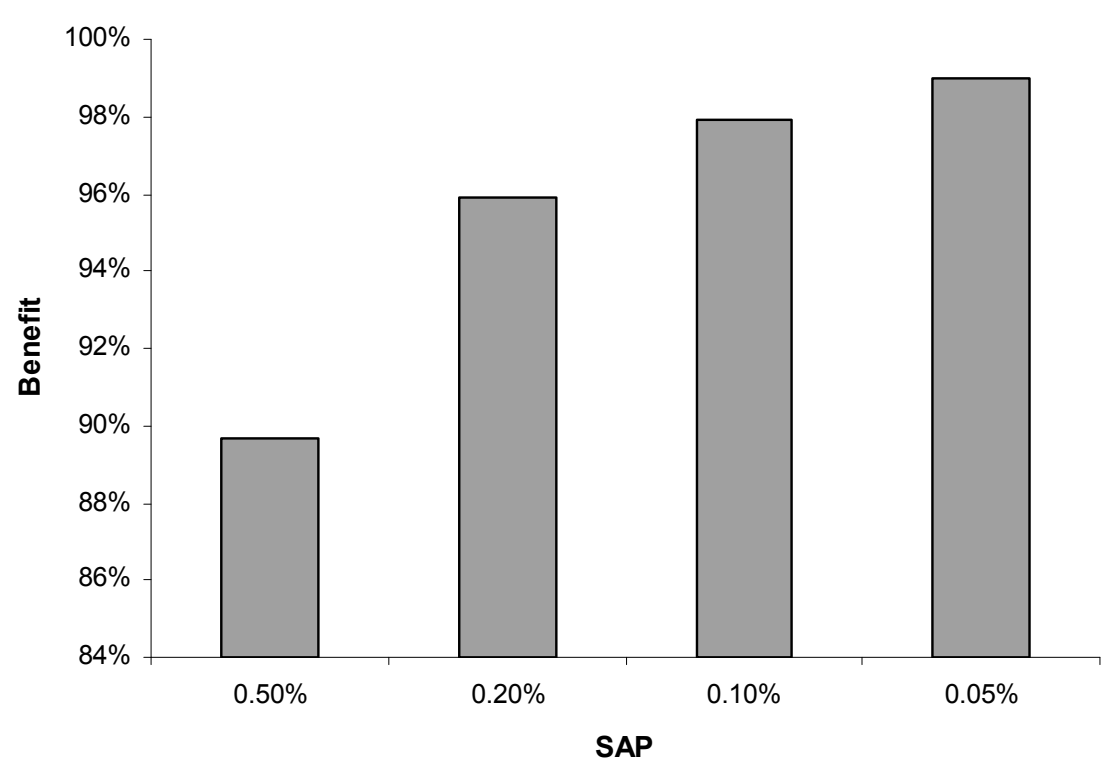

Figure 7 Relative benefit realisation when using PMP material as compared to a conventional 12\% bentonite-sand mixture

\section{$4 \quad$ Summary and conclusions}

The following conclusions can be drawn based on the results obtained:

- The possibilities of using polymer modified-paste fill mixtures as barrier materials appear to be very promising owing to their good hydraulic performance and the reduced cost from the low admixture amount necessary to further improve performance. In the compacted PMP material mixes, hydraulic conductivity is always found to be less and decreasing after the OMC. The hydraulic conductivity of PMP decreases as the content of SAP increases.

- The cyclic freeze-thaw stresses appear to increase the hydraulic conductivity of PMP. None of the samples develop hydraulic conductivity changes in order of magnitude. The good response of the composite material to freeze-thaw stresses may be due to possible resealing of micro-cracks with a self healing property entailed by high swelling additives. However, it should be mentioned that although the increase in hydraulic conductivity is lower than one order of magnitude, the PMP samples with $0.2 \%, 0.1 \%$ and $0.05 \%$ SAP content can show hydraulic conductivity values slightly higher than the minimum value $\left(1 \times 10^{-7} \mathrm{~cm} / \mathrm{s}\right)$ required for liner design in accordance to the EPA. Consequently, precautions must be taken to avoid exposing a compacted PMP barrier to drying and frost during construction and service. Otherwise, PMP materials may be unsuitable for waste containment applications where control measures are not implemented for frost penetration.

- The PMP materials demonstrate good resistance to wet-dry stresses. This is particularly attributed to the high water retention ability and the self-healing properties of the SAP.

- The cost of a conventional barrier material made of bentonite $(12 \%)$ and sand is higher than any of the studied amounts of SAP required to be mixed in the paste fill to achieve the recommended low conductivity. The benefit realised could be estimated as 98,96 and $90 \%$ when using PMP material that contains $0.10,0.20$ and $0.5 \%$ of SAP polymer.

- Despite the encouraging results obtained, further studies are necessary to provide a better understanding of the performance properties of the proposed barrier materials such as the long term behaviour and resistance to chemical attacks of the barrier materials. Research in this area has not been completed for the project in this paper, but currently being implemented in a new project. 


\section{Acknowledgements}

The writers would like to acknowledge the National Sciences and Engineering Research Council of Canada (NSERC), the University of Ottawa, and the National Research Council (NRC) of Canada.

\section{References}

ARK (2003) The ARK Enterprises, Inc. PO box 725, Peculiar, Missouri 6407., viewed January 2010 , http://www.arkent.com/products/aqua_sorb.html.

Benson, C.H. and Othman, M.A. (1993) Hydraulic conductivity of compacted clay frozen and thawed in-situ, Journal of Geotechnical Engineering, ASCE, Vol. 119(2), pp. 276-294.

Daniels, J.L., Inyang H. and Iskandar, I.K. (2003) Durability of Boston blue clay in waste containment applications, Journal of Materials in Civil Engineering, Vol. 15(2), pp. 144-152.

Eigenbrod, K.D. (2003) Self-healing in fractured fine grained soils. Canadian Geotechnical Journal, Vol. 40(2), pp. 435-449.

Fall, M., Adrien, D., Célestin, J.C., Pokharel, M. and Touré, M. (2009) Saturated hydraulic conductivity of cemented paste backfill, Journal Minerals Engineering, Vol. 18, pp. 1307-1017.

Fall, M., Célestin, J.C. and Han, F.S. (2009b) Suitability of benonite-paste tailings as engineering barrier material for mine waste containment facilities, Journal Minerals Engineering, Vol. 22, pp. 840-848.

Fall, M. and Merkel, B. (eds) (2001) Kontamination aus der Nutzung von Ressourcen - Probleme und Lösungen, In Proceedings First conference of Geo-Environment of the Graduatenkolleg (272), Geowissenschaftliche und Geotechnische Umweltforschung - TU Freiberg - Germany, Wissen. Mitt. Institut für Geologie.; Heft 18. 20 Beiträge, $200 \mathrm{p}$.

Kashir, M. and Yanful, E.K. (2001) Hydraulic conductivity of bentonite permeated with acid mine drainage, Canadian Geotechnical Journal, Vol. 38(5), pp. 1034-1048.

Qiu, Y.J. and Sego, D.C. (2001) Laboratory properties of mine tailings, Canadian Geotechnical Journal, Vol. 38 (1), pp. $183-190$.

Wong, L.C. and Haug, M.D. (1991) Cyclical closed-system freeze-thaw permeability testing of soil liner and cover materials, Canadian Geotechnical Journal, Vol. 28, pp. 784-793. 